\title{
Analysis of Drilling Fluid Circulating Pressure Loss in Hole Annulus for Microhole Drilling
}

\author{
Hou Xuejun ${ }^{1,2, *}$, Zheng Huikai ${ }^{3}$ and Gao Longzhu ${ }^{1}$
}

${ }^{1}$ College of Petrol Engineering, Chongqing University of Science and Technology, Chongqing 401331, China; ${ }^{2}$ Harold Vance Department of Petroleum Engineering, Texas A\&M University, College Station, TX, 77840, USA; ${ }^{3}$ Tianjin Boxing Science and Technology Engineering Ltd, Offshore Oil Engineering Ltd. of PetroChina, Tianjin 300451, China

\begin{abstract}
The microhole drilling (MHD) technology is one of cutting-edge drilling technologies with wellbore diameter less than $88.9 \mathrm{~mm}$ and taking coiled tubing (CT) as drilling string to deliver the bottomhole assembly to drill ahead. The normal circulation of drilling fluid is affected because of huge annulus drilling fluid circulating pressure loss (ADFCPL) caused by small diameter wellbore, narrow hole annulus and deep well. For three flow regimes of power-law fluid in MHD, the computing models of ADFCPL are built by analyzing the relationships among annulus drilling fluid parameters according to power law fluid flow state equation. The ADFCPL with different flow rate, CT diameter, well depth, eccentricity and so on is calculated for the hole annulus of MHD. The calculation results show that: in $89 \mathrm{~mm}$ diameter MHD, the ADFCPL is huge. It increases with the increase of outer diameter of CT and average flow rate of drilling fluid, and increases linearly with the increase of well depth, and decreases with the increase of eccentricity. The bigger the hole annulus is, and the lower the flow rate is, the less the impact of eccentricity acts on the ADFCPL is. Thus, the ADFCPL can be reduced by decreasing the outer diameter of $\mathrm{CT}$ and the average flow rate of drilling fluid in hole annulus. Only low flow rate can be used to drill deep well. The research results may be useful for MHD parameter selections related to the ADFCPL
\end{abstract}

Keywords: Circulating pressure loss, coiled tubing, eccentricity, hole annulus, microhole drilling.

\section{INTRODUCTION}

The MHD technology is one of cutting-edge drilling technologies with wellbore diameter less than $88.9 \mathrm{~mm}$ and taking CT as drilling string to deliver the bottom hole assembly to drill ahead [1]. It was first proposed by USA Los Alamos National Laboratory (LANL) [1] in 1994 and supported by DOE $[2,3]$ for several times. Because it has many merits [4], such as efficient and low cost, environmental protection, easy to achieve drilling informatization, automation and intelligentization and so on, it has been developed quickly.

However, drilling fluid circulating pressure loss (CPL) in micro-hole is huge because of the small diameter wellbore. The total CPL mainly consists of CPL in CT coiled around reel, CPL in downhole CT, CPL of drill bit and CPL in hole annulus, lots of studies on CPL in convention wellbore and slim hole have been studied by domestic and foreign scholars. Walton et al. [5] designed the hydraulic pressure of CT drilling, and McCann [6] studied the CPL of turbulent fluid in CT. Azouz and Shah [7] conducted experiment researches CPL in CT. Medjani and Shah [8] predicted the CPL of nonNewtonian fluid in CT. Willingham and Shah [9] studied the CPL of Newtonian fluid and non-Newtonian fluid in CT in vertical well section and reel. Shah $[10,11]$ studied the

*Address correspondence to this author at the College of Petrol Engineering, Chongqing University of Science and Technology, Chongqing 401331, China, Tel: 337-349-4528;

E-mails: xuejun_hou_2013@163.com, boxking2013@126.com influence of cuttings on CPL and predicted the fracturing CPL in CT. Rao $[12,13]$ studied the impact factors of frictional CPL for non-Newtonian fluid in CT. Ma Dongjun [14] studied a model of calculating the CPL in coiled tubing ultrashort radius radial drilling. Hou Xuejun [15] analyzed the flow resistance in coiled tubing wound around a reel in microhole drilling. Zhou [16] studied the power law fluid CPL in $\mathrm{CT}$ by theoretical and experimental methods. Song Xuncheng [17] provided the prediction method for microhole ADFCPL. Niu Tao [18] studied the CPL in microhole circulation system. However, few researches about microhole ADFCPL have been reported so far. The calculation models of ADFCPL on three flow regimes for power-law fluid in MHD are built by analyzing the relationships among annular drilling fluid parameters according to power law fluid flow state equation. The ADFCPL with different flow rate, CT diameter, well depth, eccentricity and so on is calculated and the change rules are obtained. This study can provide references for the parameters design of micro-hole annulus drilling fluid circulation.

\section{CALCULATION MODEL OF ADFCPL IN MICRO- HOLE}

\subsection{Rheological Equation of Power-Law Fluid}

In conventional drilling process, the actual rheological curve of drilling fluid is relatively close to power-law fluid. Thus, rheological model of power-law fluid is used to calculate the ADFCPL, its corresponding rheological equation, parameters and calculation model [19] are described as follows: 


$$
\left\{\begin{array}{l}
\tau=K\left(\frac{d u}{d y}\right)^{n} \\
n_{a}=0.5 \log _{10}\left(\frac{\phi_{300}}{\phi_{3}}\right) \\
K_{\mathrm{a}}=\frac{0.511 \phi_{300}}{511^{n_{a}}}
\end{array}\right.
$$

Where, $\phi_{300}$ and $\phi_{3}$ stand for the readings of rotary viscometer while its rotate speed is $300 \mathrm{r} / \mathrm{min}$ and $3 \mathrm{r} / \mathrm{min}$ respectively; $K_{a}$ is the consistency coefficient of annulus powerlaw fluid and it is depended by fluid property, dyn.s $\mathrm{s}^{n} \mathrm{~cm}^{2}$; $n_{a}$ stands for the rheological index (liquidity index) of annulus power-law fluid, non-dimensional, it represents the degree that the annular fluid deviates from Newtonian fluid; $\tau$ is shear stress, $P a$.

\subsection{Calculations of Reynolds Number and ADFCPL}

Reynolds Number represents the ratio of inertia force and viscosity force, and it is the basis of judging fluid flow regimes. As for the power-law fluid in hole annulus for CT MHD, the calculation equation of Reynolds Number can be expressed as follows:

$$
R_{e}=\frac{\rho\left(D_{h}-D_{0}\right)^{n_{a}} v_{a}^{2-n_{a}}}{12^{n_{a}-1} K_{a}\left(\frac{2 n_{a}+1}{3 n_{a}}\right)^{n_{a}}}
$$

Where, $D_{h}$ is the diameter of microhole, $\mathrm{m} ; D_{0}$ is the outer diameter of CT used in the MHD, $\mathrm{m} ; v_{a}$ stands for the average flow rate in hole annulus, $\mathrm{m} / \mathrm{s} ; R_{e}$ is the Reynolds number, non-dimensional; $\rho$ is the density of circulating drilling fluid in annulus hole, $\mathrm{kg} / \mathrm{m}^{3}$; the other symbols are the same as above.

As for the annulus between CT and wellbore, the calculation equation of ADFCPL can be expressed as follows:

$$
\Delta P_{a}=\frac{2 f L \rho v_{a}^{2}}{D_{h}-D_{0}}
$$

Where, $\Delta P_{a}$ is the drilling fluid CPL in the $L$-length annulus hole under different flow regimes, $\mathrm{Pa}$; $L$ is the length of annulus hole, $\mathrm{m} ; f$ stands for the Fanning friction factor of annulus drilling fluid under different flow regimes, nondimensional; the other symbols are the same as above.

\subsection{Flow Regimes Distinguish and Friction Factor Calcu- lation}

Suppose the discriminant factors $C_{1}$ and $C_{2}$ are expressed as Eq. (4), by comparing Reynolds Number with $C_{1}$ and $C_{2}$, different flow regimes of power-law fluid and its corresponding Fanning friction factors [10] can be expressed as follows:
$\left\{\begin{array}{l}C_{1}=3470-1370 n_{a} \\ C_{2}=4270-1370 n_{a}\end{array}\right.$

(1) While $\operatorname{Re}<C_{1}$, the fluid flow regime in the hole annulus between microhole wall and CT is laminar flow, and its corresponding calculation equation of Fanning friction factor [20] can be expressed as follows:

$f=\frac{24}{R_{e}}$

Where, all symbols are the same as above. The ADFCPL in laminar flow can be calculated by substituting $f$ and $R_{e}$ into the equation of $\Delta P_{a}$.

(2) While $\operatorname{Re}>C_{2}$, the fluid flow regime in the hole annulus between microhole wall and CT is turbulent flow, and its corresponding calculation equation of Fanning friction factor [20] can be expressed as follows:

$$
\left\{\begin{array}{l}
f=\frac{a}{R_{e}^{b}} \\
a=\frac{\lg n+3.93}{50} \\
b=\frac{1.75-\lg n}{7}
\end{array}\right.
$$

Where, $a$ and $b$ are the calculation coefficients; all symbols have the same as above. The ADFCPL in turbulent flow can be calculated by substituting $f, R_{e}, a$ and $b$ into the calculation equation of $\Delta P_{a}$.

(3) While $C_{1} \leq R_{e} \leq C_{2}$, the fluid flow regime in the hole annulus between microhole wall and CT is transitional flow, and its corresponding calculation equation of Fanning friction factor [20] can be expressed as follows:

$$
f=\frac{24}{C_{1}}+\left(\frac{a}{C_{2}^{b}}+\frac{24}{C_{1}}\right) \frac{R_{e}-C_{1}}{800}
$$

Where, all symbols have the same as above. The ADFCPL in transitional flow can be calculated by substituting $f$ and $R_{e}$ into the equation of $\Delta P_{a}$.

\subsection{Correction Model of Eccentric ADFCPL}

In MHD, the CT always tends to lean against on the low side wall of hole, which would result in an eccentricity of CT in wellbore (Fig. 1). The eccentricity of CT in wellbore will have an impact on the ADFCPL, and the extent of the impact is relevant to the eccentricity [21]. Thus, the eccentric correction factor $C_{e f}$ is introduced to correct the calculation results of ADFCPL. The correction calculation of eccentric ADFCPL is very complicate, so the structural flow is considered as turbulent flow conventionally. Thus, the calculation models of eccentricity in different flow regimes can be expressed as follows:

$$
E_{c}=\frac{2 \delta}{D_{h}-D_{0}}
$$


While the flow regime is laminar flow, the computing models of eccentric correction factor can be expressed as follows:

$C_{e f}=1-0.072 \frac{E_{c}}{n_{a}}\left(\frac{D_{0}}{D_{h}}\right)^{0.8454}-1.5\left(E_{c}\right)^{2} \sqrt{n_{a}}\left(\frac{D_{0}}{D_{h}}\right)^{0.1852}+0.96\left(E_{c}\right)^{3} \sqrt{n_{a}}\left(\frac{D_{0}}{D_{h}}\right)^{0.2527}$

While the flow regime is turbulent flow, the computing models of eccentric correction factor can be expressed as follows:

$C_{e f}=1-0.048 \frac{E_{c}}{n_{a}}\left(\frac{D_{0}}{D_{h}}\right)^{0.8454}-\frac{2}{3}\left(E_{c}\right)^{2} \sqrt{n_{a}}\left(\frac{D_{0}}{D_{h}}\right)^{0.1852}+0.285\left(E_{c}\right)^{3} \sqrt{n_{a}}\left(\frac{D_{0}}{D_{h}}\right)^{0.252}$

Where, $E_{c}$ stands for the eccentricity, which is the ratio of the offset between CT center and wellbore center to the difference between wellbore diameter and CT diameter (Fig. 1), the CT eccentricity in microhole is difficult to determine because the CT eccentricity can't be measured in real-time under complicated downhole conditions, the approximate value will be used in the calculation process, such as, its value is $0.50 \sim 0.75$ for the vertical wellbore, its value is $0.75 \sim 0.95$ for the horizontal wellbore; $\delta$ is the offset distance between CT axis and wellbore axis (Fig. 1), m; $C_{e f}$ stands for the correction factor of $\mathrm{CT}$ eccentricity in microhole, it is the ratio of ADFCPL while the CT is eccentric in wellbore to the ADFCPL while the CT and wellbore is concentric [22], when $\mathrm{CT}$ and wellbore is concentric, $E_{c}$ equals to 0 and $C_{e f}$ equals to 1.0 , while the CT is pressed firmly against the borehole wall, $E_{c}$ equals to 1 and $C_{e f}$ is the smallest; the other symbols are the same as above.

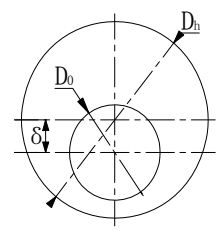

(a) $\left(\begin{array}{l}0 \prec \delta \prec\left(D_{h}-D_{0}\right) / 2 \\ E_{c}=2 \delta /\left(D_{h}-D_{0}\right)\end{array}\right)$

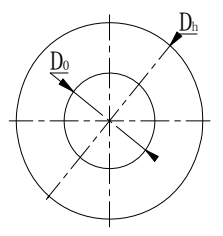

(b) $\left(\begin{array}{l}\delta=0 \\ E_{c}=0\end{array}\right)$

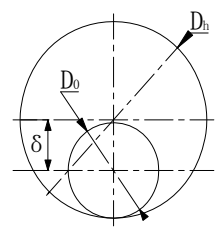

(c) $\left(\begin{array}{l}\ddot{\delta}=\left(D_{h}-D_{0}\right) / 2 \\ E_{c}=1\end{array}\right)$
Fig. (1). Eccentricity $(E c)$ of Coiled Tubing in Microhole.

\section{EXAMPLE ANALYSIS OF ADFCPL IN MHD}

\subsection{Examples of Parameter Selection}

Suppose the density of drilling fluid in hole annulus is $1.5 \mathrm{~g} / \mathrm{cm}^{3}, \phi_{300}$ is 12 and $\phi_{3}$ is 3 based on the CT (Table 1) used in the $89 \mathrm{~mm}$ diameter microhole and the properties of low-solid content and low-viscosity drilling fluid. ADFCPL in $89 \mathrm{~mm}$ diameter microhole can be calculated by using Eq. (1) (10).

\subsection{Example Analysis of ADFCPL}

ADFCPL with different diameter CT is calculated by using above parameters, and the results are plotted and analyzed respectively.

\section{(1) Change Rules of ADFCPL with Certain Well Depth}

ADFCPL increases rapidly with the increasing of drilling fluid flow rate (Fig. 2) and the increasing of CT outer diameter (Fig. 3). That's, the higher the flow rate is and the larger the outer diameter of CT is, the larger the increment of ADFCPL is.

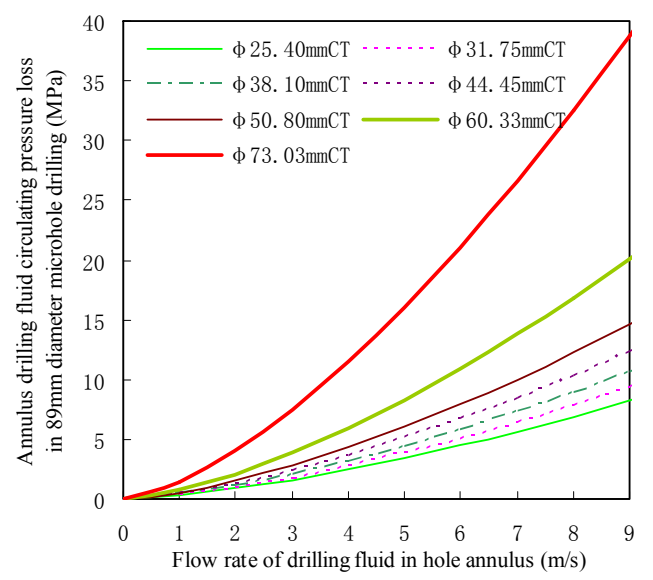

Fig. (2). ADFCPL Curves with Flow Rates in $98 \mathrm{~mm}$ Diameter Microhole of $2000 \mathrm{~m}$ Depth.

The ADFCPL are large because of the small diameter wellbore and the small hole annulus, which will seriously affect the rational utilization of drilling fluid hydraulic energy. Thus, the ADFCPL is reduced by using the smaller diameter CT to increase the sectional area of hole annulus.

\section{(2) Change Rules of ADFCPL with Well Depth}

Suppose the drilling fluid flow rate in hole annulus is constant, the computed results of ADFCPL (Fig. 4) in $98 \mathrm{~mm}$ diameter microhole with different well depth show that:

The ADFCPL increases linearly with the increasing of well depth. Simultaneously, the larger the outer diameter of $\mathrm{CT}$ is and the smaller the hole annulus is, the larger the increment of ADFCPL is. In this example analysis, it is the fastest increase of ADFCPL for $73.025 \mathrm{~mm}$ diameter $\mathrm{CT}$ and the lowest increases of ADFCPL for $24.5 \mathrm{~mm}$ diameter CT in hole annulus.

While the $73.025 \mathrm{~mm}$ diameter CT is used in MHD, the ADFCPL is affected severely by the flow rate. While the flow rate of drilling fluid is $2 \mathrm{~m} / \mathrm{s}$, the ADFCPL of $8000 \mathrm{~m}$ depth well is $12.381 \mathrm{MPa}$. While the flow rate of drilling

Table 1. Coiled tubing parameter list [23].

\begin{tabular}{|l|c|c|c|c|c|c|c|}
\hline Outer diameter(mm) & 25.4 & 31.750 & 38.100 & 44.450 & 50.800 & 60.325 & 73.025 \\
\hline Wall thickness $(\mathrm{mm})$ & 3.175 & 3.962 & 3.962 & 3.962 & 3.962 & 3.962 & 3.962 \\
\hline Inner diameter(mm) & 19.05 & 23.826 & 30.176 & 36.526 & 42.876 & 52.401 & 65.101 \\
\hline
\end{tabular}




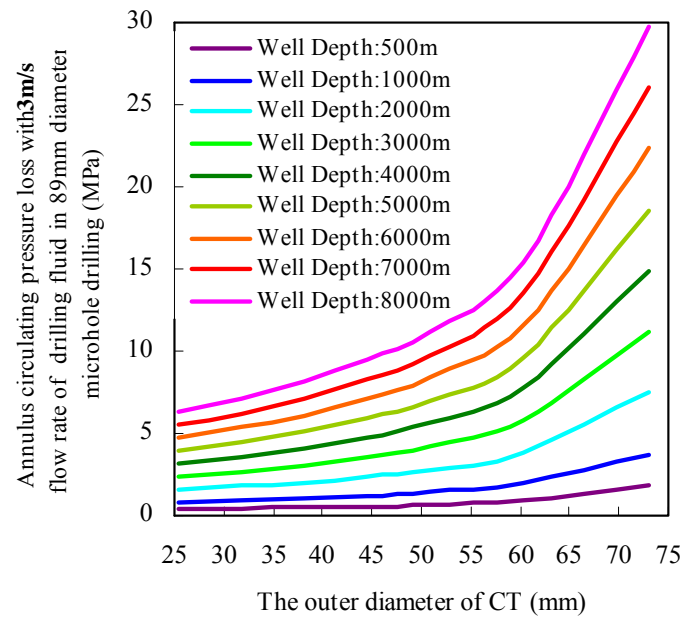

(a) When Flow Rate is $3 \mathrm{~m} / \mathrm{s}$

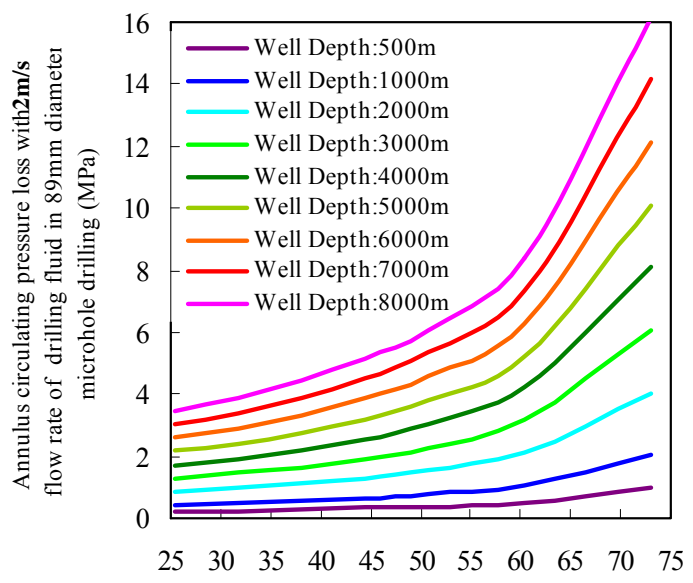

The outer diameter of CT (mm)

(b) When Flow Rate is $2 \mathrm{~m} / \mathrm{s}$

Fig. (3). ADFCPL Curves with Outer Diameter of CT in Diameter 98mm Microhole.

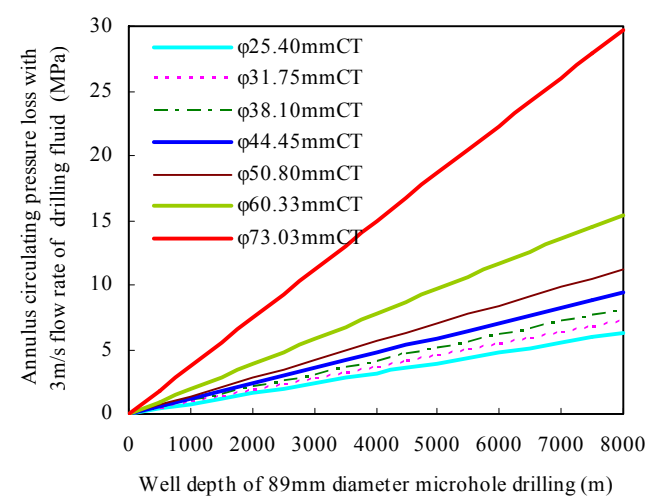

(a) ADFCPL Curves When Flow Rate is $3 \mathrm{~m} / \mathrm{s}$

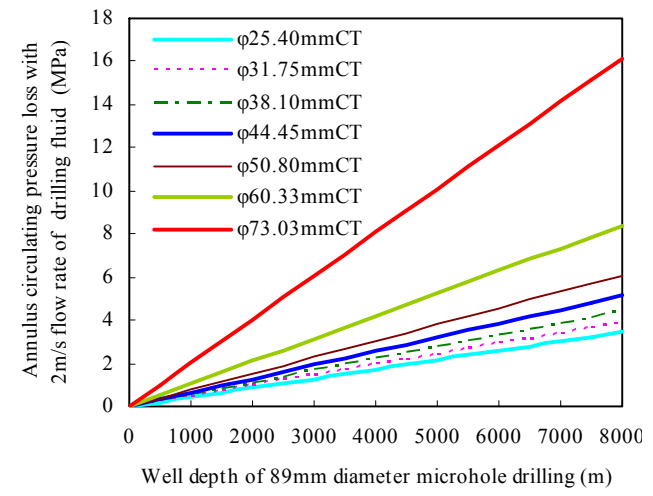

(b) ADFCPL Curves When Flow Rate is $2 \mathrm{~m} / \mathrm{s}$

Fig. (4). ADFCPL curves with well depth in $98 \mathrm{~mm}$ diameter microhole.

fluid is $3 \mathrm{~m} / \mathrm{s}$, the ADFCPL of $8000 \mathrm{~m}$ depth well is 26.733MPa. Considering the pump capacity, the $12.381 \mathrm{MPa}$ pressure loss can meet the pump requirement while ADFCPL in other sections is little. However, the $26.733 \mathrm{MPa}$ CPL is too high and the surface pump can hardly meet its requirement when other sections CPL exist. Thus, when the $98 \mathrm{~mm}$ diameter microhole for depth of $8000 \mathrm{~m}$ is drilled with $73.025 \mathrm{~mm}$ diameter $\mathrm{CT}$, the flow rate of drilling fluid in hole annulus should not exceed $2 \mathrm{~m} / \mathrm{s}$.

In the $89 \mathrm{~mm}$ diameter MHD, the diameter of $60.325 \mathrm{~mm}$ $\& 50.8 \mathrm{~mm} \& 44.45 \mathrm{~mm}$ can be used to reduce the ADFCPL while the increment of CPL in CT is small.

\section{(3) Impact of Eccentricity on ADFCPL}

ADFCPL is changed because of the offset between the axis of CT and the axis of microhole. Suppose the flow rate is $3 \mathrm{~m} / \mathrm{s}$ or $2 \mathrm{~m} / \mathrm{s}$, the results of ADFCPL in $89 \mathrm{~mm}$ diameter microhole with different $E c$ are shown as follows (Fig. 5).

Even though the ADFCPL can be decreased by the increasing of CT eccentricity in hole annulus, the frictional resistance between $\mathrm{CT}$ and wellbore wall and the borehole problems will increase with the increasing of CT eccentricity in hole annulus. Thus, a high strength CT should used in the field to reduce the $\mathrm{CT}$ eccentricity in hole annulus.
The impact of eccentricity on ADFCPL is relevant to eccentric annular clearance, the larger the CT diameter is, the smaller the eccentric annular clearance is, then the impact of eccentricity on ADFCPL is larger, or vice versa (Fig. 5). Thus, the degree of the impact of eccentricity can be reduced by selecting smaller diameter CT to increase the eccentric annular clearance.

The impact of eccentricity on ADFCPL is also relevant to the flow rate of drilling fluid in hole annulus, the higher the flow rate is, the larger the degree of the impact of eccentricity on ADFCPL is. Thus, the degree of the impact of eccentricity on ADFCPL can be reduced by decreasing drilling fluid flow rate in hole annulus while the rate can meet other requirements.

\section{CONCLUSIONS}

(1) As for the $89 \mathrm{~mm}$ diameter MHD, the ADFCPL is large. Considering the surface pump capacity and rational utilization of hydraulic power, CT with small diameter can be used to reduce the ADFCPL, and only small flow rate of drilling fluid can be used in deep MHD.

(2) As for the $89 \mathrm{~mm}$ diameter MHD, the ADFCPL increases quickly with the increasing of drilling fluid 


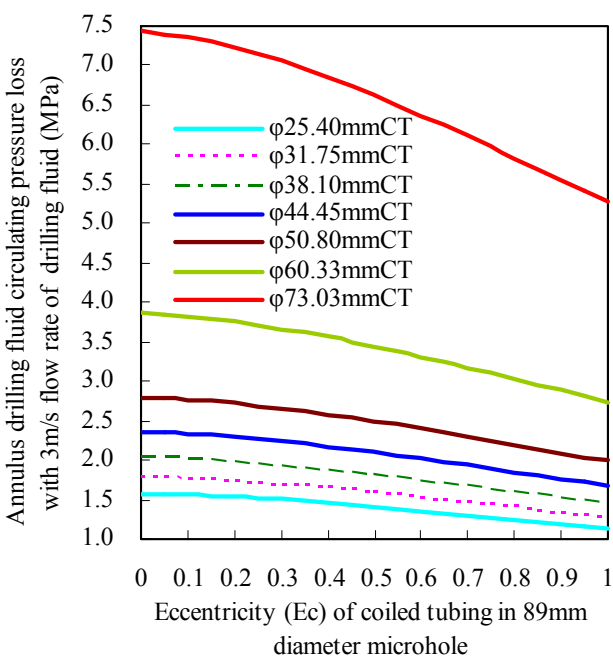

(a) ADFCPL Curves When Flow Rate is $3 \mathrm{~m} / \mathrm{s}$

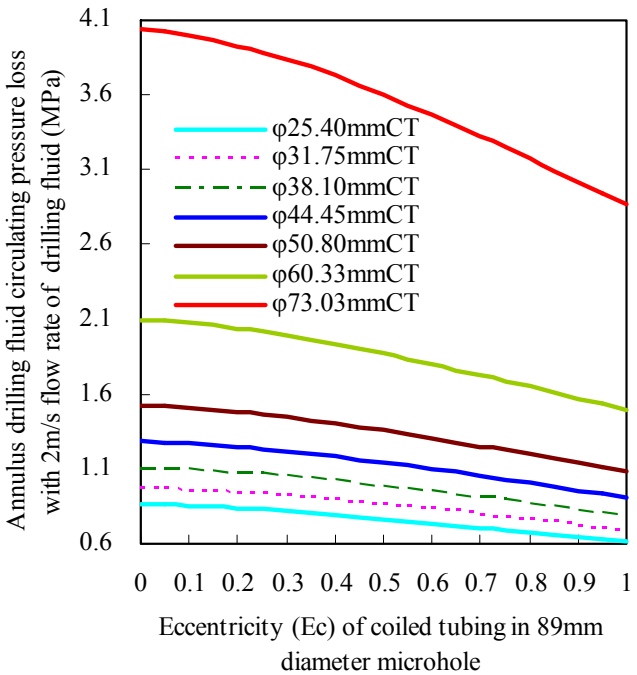

(b) ADFCPL Curves When Flow Rate is $3 \mathrm{~m} / \mathrm{s}$

Fig. (5). ADFCPL curves with different eccentricity $(E c)$ and CT in $89 \mathrm{~mm}$ diameter microhole.

flow rate and outer diameter of CT. Thus, the ADFCPL can be reduced by decreasing flow rate and outer diameter of CT.

(3) As for the $89 \mathrm{~mm}$ diameter MHD, the ADFCPL increases linearly with the increasing of well depth, the larger the CT outer diameter is, the smaller the annular clearance is, and the larger the ADFCPL is. So the smaller outer diameter CT than $73.025 \mathrm{~mm}$ outer diameter, such as $60.325 \mathrm{~mm}, 50.8 \mathrm{~mm}, 44.45 \mathrm{~mm}$, can be used to drilling deep microhole for reducing the ADFCPL.

(4) As for the $89 \mathrm{~mm}$ diameter MHD, the ADFCPL decreases with the increasing of eccentricity. The larger the eccentric annular clearance is, the smaller the degree of the impact of eccentricity on the ADFCPL is. The lower the flow rate is, the smaller the degree of the impact of eccentricity on the ADFCPL is. Thus, the downhole borehole problems can be reduced by using small diameter CT \& flow rate to reduce the impact of eccentricity on the ADFCPL.

\section{CONFLICT OF INTEREST}

The authors confirm that this article content has no conflicts of interest.

\section{ACKNOWLEDGEMENTS}

The authors gratefully acknowledge the financial support of the Natural Science Foundation of China (NSFC,51374266), the Basic and Frontier Research Project by Chongqing Science and Technology Commission of China (Grant No.: cstc2013jcyjA90011), the Scientific and Technological Research Program of Chongqing Municipal Education Commission of China (Grant No.: KJ131413), the Key Cultivation Fund Projects (Grant No.: CK2013Z07) and Scientific Research Funds Projects of Chongqing University of Science \& Technology of China (Grant No.: CK2013Z07) and the Education Reform Project of Chongqing University of Science \& Technology of China (Grant No.: 201140).

\section{REFERENCES}

[1] A. Jim, D. Don, A. Dave, and B. Jim, "Road map for a 5000-ft microborehole", Los Alamos National Laboratory, pp. 1-4, 2005.

[2] DOE, "DOE to Support 'Small Footprint' Technologies for Oil and Gas Fields", www.fossil.energy.gov, 2004.

[3] DOE, "DOE Announces R\&D funding for microhole technology projects", www.fossil.energy.gov, 2005.

[4] K. Perry, S. Bataresh, S. Gowelly, and T. Hayes, "Field demonstration of exiting microhole coiled tubing rig (MCTR) technology final technical report", Gas Technology Institute, pp. 1-8, 2006.

[5] W. C. Ian, and H. Gu, "Hydraulics design in coiled tubing drilling", Society of Petroleum Engineers, vol. 36349, pp. 1-10, 1996.

[6] R.C. McCann, and C.G. Islas, "Frictional pressure loss during turbulent flow in coiled tubing", Society of Petroleum Engineers, vol. 36345, pp. 1-6, 1996.

[7] I. Azouz, S.N. Shah, P.S. Vinod, and D.L. Lord, "Experimental investigation of frictional pressure losses in coiled tubing", Society of Petroleum Engineers Production \& Facilities, vol. 13, pp. 91-96, 1998.

[8] B.Medjani, and S.N.Shah, "A new approach for predicting frictional pressure losses of non-newtonian fluid in coiled tubing", Society of Petroleum Engineers, vol. 60319, pp. 1-12, 2000.

[9] J. D. Willingham, and S. N. Shah, Friction pressures of newtonian and non-newtonian fluids in straight and reeled coiled tubing", Society of Petroleum Engineers, vol. 60719, pp. 1-13, 2000.

[10] S. N. Shah, and Y. Zhou, "An experimental study of the effects of drilling solids on frictional pressure losses in coiled tubing", Society of Petroleum Engineers, vol. 67191, pp. 1-15, 2001.

[11] S Shah, Y. X. Zhou, M. Bailey, and J. Hernandez, "Correlations to predict frictional pressure loss of hydraulic fracturing slurry in coiled tubing", Society of Petroleum Engineers Production \& Operations, vol. 104253, pp. 381-395, 2009.

[12] B. N. Rao, "Friction factor for turbulent flow of non-newtonian fluid in coiled tubing", Society of Petroleum Engineers, vol. 74847, pp. 1-12, 2002.

[13] Y. Zhou, and S. N. Shah, "New friction-factor correlations for nonnewtonian fluid flow in coiled tubing", Society of Petroleum Engineers Drilling \& Completion, vol. 77960, pp. 68-76, 2006.

[14] D. J. Ma, G. S. Li, Z. W. Huang, J. L. Niu, C. Hou, Mi. J. Liu, and J. B. Li, "A model of calculating the circulating pressure loss in coiled tubing ultra-short radius radial drilling", Petroleum Exploration and Development, vol. 39, no. 4, pp. 528-533, 2012.

[15] X. J. Hou, D. L. Gao, and Z. H. Shen, "An analysis of the flow resistance in coiled tubing wound around a reel, in microhole drilling", CMES - Computer Modeling in Engineering and Sciences, vol. 89, no. 2, pp. 97-109, 2013. 
[16] Y. Zhou, "Theoretical and experimental studies of power-law fluid flow in coiled tubing", Oklahoma: The University of Oklahoma, 2006.

[17] X. C. Song, G. C. Wang, Z. C. Guan, and D. Y. Zou, "A method for computing the circulating pressure loss in slimhole annulus", Petroleum Drilling Techniques, vol. 32, no. 6, pp.11-12, 2004.

[18] T. Niu, H. W. Liang, and Y. J. Xu, "Study on the pressure loss laws in micro hole circulatory system", Drilling \& Production Technology, vol. 32, no. 4, pp. 31-33, 2009.

[19] H. L. Zhao, Z. H. Ke, and Z. F. Zhao, "Development and Application on Slimhole and Coiled Tubing Technology", Beijing: Petroleum Industry Press, pp. 40-41, 1998.
[20] B. N. Rao, "Friction factors for turbulent flow of non-newtonian fluids in coiled tubing", Society of Petroleum Engineers, vol. 74847, pp. 1-12, 2000.

[21] H. J. Zhang, and J. Z. Wu, "Spiral flow analytical solution for nonnewtonian fluid in eccentric annulus", Applied Mathematics and Mechanics, vol. 15, no. 7, pp. 627-638, 1994.

[22] H. G. Wang, and Y. N. Su, "A practical method of determination of pressure loss in eccentric annulus", Oil Drilling \& Production Technology, vol. 19, no. 6, pp. 5-9, 1997.

[23] Z. M. Zhao, "Coiled Tubing Engineering Technical Manual", Beijing: Petroleum Industry Press, pp. 71-78, 2011.

(C) Xuejun et al.; Licensee Bentham Open.

This is an open access article licensed under the terms of the Creative Commons Attribution Non-Commercial License (http://creativecommons.org/licenses/by-nc/3.0/) which permits unrestricted, non-commercial use, distribution and reproduction in any medium, provided the work is properly cited. 